\title{
Design para inclusão social: 0 brinquedo como ferramenta na promoção de diálogos inclusivos.
}

Design for social inclusion: The toy as a tool in promoting inclusive dialogues.

CERQUEIRA, Clara Santana Lins; Graduada; Universidade do Estado de Minas Gerais clara.slc.12@gmail.com

RIBEIRO, Rita Aparecida da Conceição; Doutora; Universidade do Estado de Minas Gerais rribeiroed@gmail.com

\section{Resumo}

Este artigo tem como foco abordar de que maneira o design contribui para a fabricação de brinquedos que dialoguem com as identidades dos indivíduos que têm deficiência física diante da sociedade de consumo. Portanto, contextualizamos a ascensão do conceito de infância, que ocorre a partir do século XIX e XX, para compreender a valorização da criança como ator social que pode fomentar mudanças de pensamento, ditando regras, gostos e preferências pessoais. Compreender o brinquedo como um objeto que representa símbolos e valores e logo podem expressar as identidades assumidas pelas crianças. Portanto, apresentar o brinquedo não só como objeto de consumo mas também como uma ferramenta poderosa de comunicação, analisando como o design se apropria desses símbolos para ressignificar objetos lúdicos promovendo, assim, a inclusão social de pessoas com deficiência física. Para tal, a metodologia utilizada foi baseada em autores que discutem o tema infância, brinquedo design e inclusão, além de considerar exemplos e estudos de casos.

Palavras Chave: brinquedos; inclusão social; design.

\begin{abstract}
This article focuses on how design contributes to the manufacture of toys that dialogue with the identities of individuals with physical disabilities. Therefore, we contextualize the rise of the concept of childhood, which occurs from the nineteenth and twentieth centuries, to understand the value of the child as a social actor that can foster changes of thinking, dictating rules, tastes and personal preferences. Understand the toy as an object that represents symbols and values and can soon express the identities assumed by children. Therefore, to present the toy as a powerful tool of communication, analyzing how the design appropriates these symbols to reignify playful objects thus promoting the social inclusion of people with physical disabilities. To that end, the methodology used was based on authors who discuss the theme of childhood, toy design and inclusion, besides considering examples and case studies.
\end{abstract}

Keywords: toys, social inclusion; design. 


\section{Introdução}

O pensamento em design constrói objetos que vão muito além das suas formas e cores, transmitindo uma linguagem que perpassa por valores simbólicos e emotivos. O mundo que nos cerca, os objetos que portamos, as nossas preferências de consumo, estilo de vida, tudo traduz no indivíduo que queremos ser e mostrar socialmente. Portanto, assume-se uma identidade que o faça se sentir percebido e aceito através desses objetos.

O contexto sócio histórico em que o indivíduo vive atualmente é acompanhado por variáveis que englobam consumo, identidade e estetização. Os objetos ao longo das décadas vêm se consolidando cada vez mais como uma forma de expressão sociocultural, assim como o brinquedo. Através desses objetos o indivíduo quer ser percebido e se fazer existir criando novos diálogos sobre valores e pertencimento.

No universo infantil essa lógica é da mesma maneira perceptível. As crianças portam diversos objetos no dia a dia que intencionam dialogar com o mundo que a cerca, sobre sua personalidade individual e gostos. Por isso, essa fase é permeada por uma intensa transmissão e absorção de símbolos e valores, e dessa forma, o seu desenvolvimento depende significativamente disso.

A indústria de brinquedos e o consumo se fazem presentes no universo deste público também e, por isso, as marcas lançam mão de vários fatores para atrair as crianças e seus pais.

Portanto, a partir de meados do século XIX quando a infância ganha seu espaço social, lentamente as indústrias percebem a criança como um nicho de mercado consumidor, ampliando sua produção de bens de consumo para esse público de maneira colossal nos séculos XX e XXI.

\section{Século XIX e XX, o brinquedo e a infância}

\subsection{O surgimento do conceito de infância}

A criança nem sempre esteve em um papel social de ser o centro das atenções e de adquirir privilégios como nos dias atuais. O próprio senso de "infância" ainda é muito recente porque até então, durante séculos, foram sistematicamente exploradas, sem obter nenhum respeito dos demais atores sociais, sem direito a voz.

A palavra "infância" vem do latim infantia, do verbo fari (falar) e o prefixo -in constitui a negação do verbo (ERNOUT e MEILLET, 1951, p.584). Portanto, o termo refere-se ao indivíduo que é incapaz de falar, mudez (FARIA, 1962, p. 494,). Assim, na própria etimologia da palavra infância, percebe-se claramente o papel pouco significativo no qual a criança já esteve inserida, até a primeira metade do século XIX.

Em meados do século XVI, nota-se, que a infância era uma repetição sistemática do mundo adulto. Um exemplo disso são as indumentárias: quando ainda bebês, a criança usava apenas cueiros. ${ }^{1}$ Até, aproximadamente, os cinco anos de idade, a vestimenta se resumia a vestidos que serviam tanto para as meninas quanto para os meninos. $E$ após essa fase as crianças se vestiam exatamente iguais às indumentárias que os pais utilizavam (ARIÈS, 2014, p.75).

\footnotetext{
${ }^{1}$ Cueiro: pano que se envolve o corpo das crianças de peito da cintura para baixo. (AURÉLIO, 1993, p. 156)
} 
Contudo, Rousseau, por volta de 1762, através dos ideais iluministas, empenha-se para promover não só uma indumentária infantil condizente com a infância mas também promover o senso de maior liberdade às crianças em seus gestos e movimentos lúdicos, pautando uma diferenciação entre as fases da vida de um ser humano. Em sua obra Emílio ou da Educação (1995) o pensador discorre referindo-se aos cueiros:

Supõe-se que as crianças em liberdade podem colocar-se em más posições e efetuar movimento suscetíveis de prejudicar a boa conformação de seus membros. Trata-se de um desses raciocínios gratuitos de nossa falsa sabedoria e que jamais uma experiência confirmou. Na multidão de crianças que, entre os povos mais sensatos do que nós, são criados com inteira liberdade de seus membros, não se vê uma só que se fira ou se estropie. (ROSSEUAU, 1995, p. 19)

Assim, o autor critica claramente as condições de tratamento pelas quais as crianças passavam, seja por crenças culturais ou por ignorância da medicina da época. Lentamente este movimento influenciou a adoção de tecidos leves nas roupas, por exemplo, além de cores mais claras e a eliminação das armações das saias das meninas como mostra a Figura 1 a seguir.

Figura 1 - Traje do século XVIII.

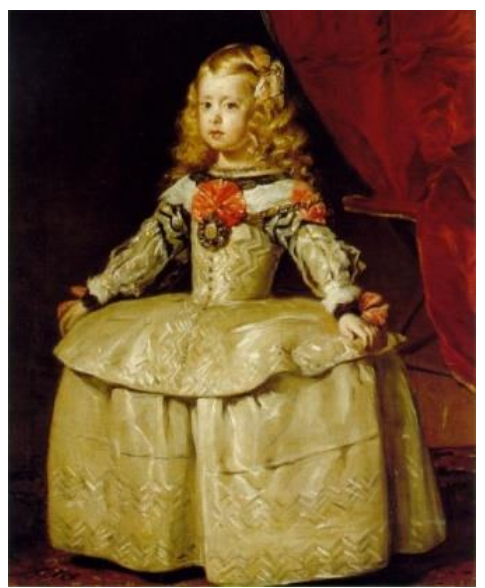

Fonte: estudodainfancia.blogspot.com.br (2012)

Por consequência, o mesmo acontecia com mercado de brinquedos da época. Primeiramente, não era necessariamente um "mercado", pois os brinquedos eram geralmente feitos por um profissional que tinha outras funções. Segundo Benjamin (2002) anteriormente ao século XIX, os brinquedos não eram fabricados por indústrias especializadas, muito menos por profissionais que se dedicavam apenas a este serviço. O brinquedo até então, segundo o autor, "era um produto secundário das diversas oficinas manufatureiras, as quais, restringidas pelos estatutos corporativos, só podiam fabricar aquilo que competia ao seu ramo." (BENJAMIN, 2002, p.90). Os brinquedos também eram mais destinados aos adultos do que para crianças. Ariès (2014) em seu livro "História Social da Criança e da Família" relata que os jogos e brincadeiras comumente faziam parte apenas no universo dos adultos nos quais as crianças eram somente introduzidas mais tarde entre 6 e 7 anos. Ele ainda disserta que os brinquedos do século XVI e XVII eram uma releitura da vida adulta, um exemplo que ele cita é o cavalo de pau em que as crianças montavam na tentativa de imitar os adultos em seus cavalos.

Na Antigüidade, certos brinquedos que faziam parte somente do universo dos adultos, por 
meio do desenvolvimento tecnológico e do surgimento da noção de infância, chegaram até hoje transformados em objetos exclusivos das crianças. Isso ocorreu nas últimas décadas do século XIX, quando a criança passou a receber atenção exclusiva, tendo como conseqüência que os brinquedos também passaram a ser foco de atenção. (MEFANO, 2005, p.08)

Dessa forma, os fabricantes de brinquedos eram pessoas que tinham habilidades e destreza no manuseio com a madeira, o metal, etc., o que na conjuntura atual, é muito raro. Hoje, essa fabricação, é caracterizada pela segmentação da mão de obra, isto é, pelo trabalho especializado e individualizado durante a montagem do produto, prática comum com o advento da Revolução Industrial.

Quando não se podia pagar pela feitura de um brinquedo era muito comum a improvisação nas brincadeiras para se ter acesso ao momento lúdico, como sempre existiu e ainda hoje existem tais hábitos, um simples cabo de vassoura, por exemplo, poderia vir a ser um cavalinho de pau, ou um barro úmido poderia ganhar formas e virar um boneco.

\subsection{A infância no contexto da Revolução Industrial}

O período da Revolução Industrial foi não só crucial para a explosão da produção de bens e serviços mas também para a exploração de toda e qualquer mão de obra. Assim como os pais, crianças trabalhavam para prover o sustento da família, quando recebiam salários, eram inferiores aos dos adultos e obviamente adquiriam e tinham hábitos muito comuns do universo sociocultural do adulto da época. Era muito comum ver crianças no intervalo do trabalho ou após o serviço, bebendo ou fumando como mostra a imagem a seguir de Lewis Hine (Figura 2), investigador chefe e fotógrafo do National Child Labor Committee (NCLC), organização privada fundada em 1904 com o intuito de promover uma legislação que protegesse crianças dos abusos das indústrias norte americanas. $^{2}$

Figura 2 - Crianças fumando, 09 de março.

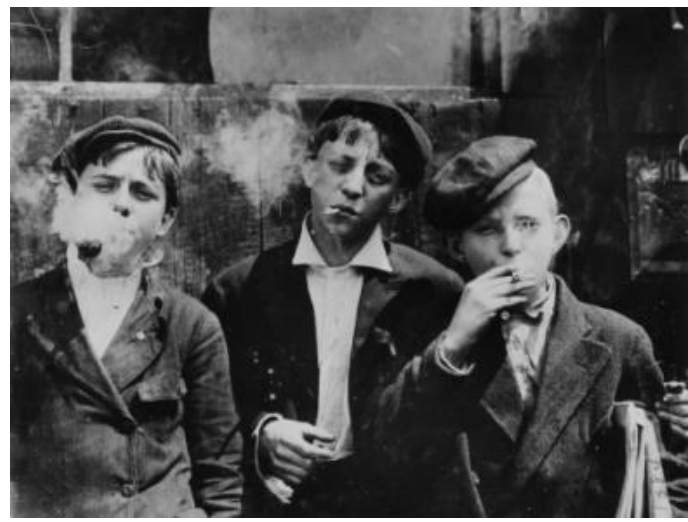

Fonte: metmuseum.org (1970)

Contudo, em 1924 Eglantyne Jebb escreve a primeira versão da Declaração dos Direitos da Criança, mais conhecida como Declaração de Genebra, que se preocupava com a valorização da infância e a naturalmente com o bem-estar das crianças. Apenas em 20 de novembro de 1959, a Declaração dos Direitos da Criança é adotada e reconhecida na Declaração Universal dos Direitos

\footnotetext{
2 Informação disponível em: https://www.metmuseum.org/toah/works-of-art/1970.727.1/. Acesso em: 30 de mar., 2018.
} 
Humanos pela Assembleia das Nações Unidas. Mudanças e comportamentos sociais irão ocorrer e, a partir desse momento, a criança que dantes era um ser que dispensava maiores preocupações, passa a ser foco da atenção sociocultural de grande parte dos países. O sexto princípio da Declaração dos Direitos da Criança diz o seguinte:

Para o desenvolvimento completo e harmonioso de sua personalidade, a criança precisa de amor e compreensão. Criar-se-á, sempre que possível, aos cuidados e sob a responsabilidade dos pais e, em qualquer hipótese, num ambiente de afeto e de segurança moral e material, salvo circunstâncias excepcionais, a criança da tenra idade não será apartada da mãe. À sociedade e às autoridades públicas caberá a obrigação de propiciar cuidados especiais às crianças sem família e aquelas que carecem de meios adequados de subsistência. É desejável a prestação de ajuda oficial e de outra natureza em prol da manutenção dos filhos de famílias numerosas. (Declaração dos Direitos da Criança, 1959).

Portanto, as décadas que estariam por vir seriam sociologicamente bem diferentes para crianças e jovens, principalmente após a Segunda Guerra Mundial, onde há a intensificação da produção do mercado de bens de consumo para essas gerações. Segundo Edgar Morin (1997), em sua obra intitulada "Cultura de massas no século XX" o pós-guerra promove o rompimento dos paradigmas dos comportamentos socioculturais do início do século XX. Se os pais anteriormente estavam no papel de transmissores da sabedoria, experiência, sinônimo de respeito e obrigados a punir os atos dos filhos para garantir o efeito ensino-aprendizado, agora "as crianças da nova idade são mimadas por seus pais como nunca foram" (MORIN, 1997, p.150). E ainda na visão do autor a infância e a juventude no século XX passam a ser procrastinadas com o intuito sociológico de rejuvenescer a sociedade mas antropologicamente esse ato é visto por ele como um "protesto ilimitado contra o mal irremediável da velhice." (MORIN, 1997, p. 157)

O mercado de brinquedos é direcionado cada vez mais para o público infantil, como seu maior alvo para venda. Assim, as mídias e as marcas irão utilizar de todo tipo de recurso e propaganda para convencer as crianças de que não poderão viver sem um determinado produto e, quem deverá pagar a conta desses novos hábitos serão os pais. Estes por sua vez, também serão alvos da lógica de mimar suas crianças. A publicidade os faz acreditar que a privação de objetos de consumo infantil significa privar a criança de sua infância além de, um desenvolvimento saudável e normal. Há um pacto social tácito em que se um pai ou uma mãe não compra os objetos que todas as outras crianças do bairro ou da escola têm, por exemplo, fará a criança se sentir excluída e diferente das outras crianças.

\section{O Século XX: O Mercado de Brinquedos no Contexto da Revolução Industrial}

O design, ou o desenho industrial, neste período veio a ser um dos motivos que alavancaram em diversos aspectos o sucesso de variados objetos como máquinas de costura e a própria indústria têxtil, cadeiras, aparelhos domésticos e não seria diferente, portanto, com o mercado de brinquedos. Esse sucesso não se deve apenas à nova aparência que esses produtos teriam, mas pelo modo como intencionavam interagir com os seus consumidores.

A efervescência cultural nos países europeus fez com que uma quantidade enorme de escolas de artes e design fossem abertas. Na Grã-Bretanha a Society for The Encouragement of Arts (hoje, Royal Society of Arts) e a Manufacture and Commerce; na Inglaterra, as Schools of Design (1837); no Rio de Janeiro a Sociedade Auxiliadora da Indústria Nacional (1831). 
O intuito das aberturas dessas escolas era revigorar foças nacionalistas, identidade e estilo de cada nação reforçando também a promoção industrial e a integração arte e indústria (CARDOSO, 2004, p. 107). Mas foi, contudo, na Alemanha em 1907 que surgiu a primeira organização com o intuito de promover o design como elemento essencial para a afirmação da identidade nacional: a Deutscher Werkbund (CARDOSO, 2004, p. 109). É neste contexto que a escola Bauhaus, fundada em Weimar, Alemanha, em 1919 se insere repensando toda a lógica de produção artística atrelada a indústria.

Contrariando a vontade de alguns dos seus idealizadores, a Bauhaus acabou contribuindo muito para a cristalização de uma estética e de um estilo específicos no design: o chamado 'alto' Modernismo que teve como preceito máximo o Funcionalismo, ou seja, a ideia de que a forma ideal de qualquer objeto deve ser determinada pela sua função, atendo-se sempre a um vocabulário formal rigorosamente delimitado por uma série de convenções estéticas bastante rígidas. (CARDOSO, 2004, p. 120)

A escola acreditava que o ornamento não tinha mais serventia para que a real função do objeto articulasse com o seu usuário. Nota-se isso através de uma série de autores, artistas, arquitetos e designers que eram adeptos ao Funcionalismo e deixaram registrados os seus pensamentos acerca do movimento, como o exemplo Adolf Loos no livro "Ornamento e Crime" (1908), onde ele disserta que "a ausência de ornamento elevou as restantes artes a um nível nunca antes imaginado." E a máxima de Louis Sullivan, que ficou muito conhecida, quando diz que "A forma segue a função".

Se tratando do universo dos brinquedos, muitos bauhausianos se aventuraram neste setor seguindo a estética da escola (Figuras 3 e 4). O que demonstra, mais uma vez, a história que esses objetos levam consigo e a importância deles como cultura material.

Os brinquedos eram vistos naquela época também como objetos que compunham o ambiente da casa. Alma Buscher, foi uma das precursoras a implementar na Bauhaus ideias educacionais com grande "versatilidade e originalidade" (MÜLLER, 2009, p. 113). Buscher, além de projetar brinquedos, também projetou diversos mobiliários e ambientes para crianças.

"Os jogos que construí para crianças eu chamo de "jogos livres" em contraste com os jogos Fröbel e Pestalozzi $i^{3}$ que foram criados na direção contrária quase sem se pensar, a partir do prazer de criar, das formas coloridas e com conhecimento dos meus próprios desejos, os quais notei em crianças com as quais eu simpatizei." (BUSCHER apud MÜLLER, 2009, p. 115) ${ }^{4}$

\footnotetext{
${ }^{3}$ Fröbel e Pestalozzi: Froebel, discípulo de Pestalozzi, idealizou recursos sistematizados para as crianças se expressarem, dando o nome de "dons" porque dizia que Deus os oferecia para que as necessidades infantis fossem bem desenvolvidas. Os chamados "dons" eram a bola, o cubo e o cilindro. Disponível em: http://frankvcarvalho.blogspot.com.br/2011/10/friedrich-froebel.html.

${ }^{4}$ Tradução da autora. No original: "The games I have built for children I call free games in contrast to the Fröbel and Pestalozzi games whinch were created in the opposite direction almost without thinking, out of the joy of creating, from colorful shapes and with knowledge of my own desires, which I noticed in children and with I empathized."
} 
Figura 3 - Brinquedos feitos por Alma Buscher, Bauhaus.

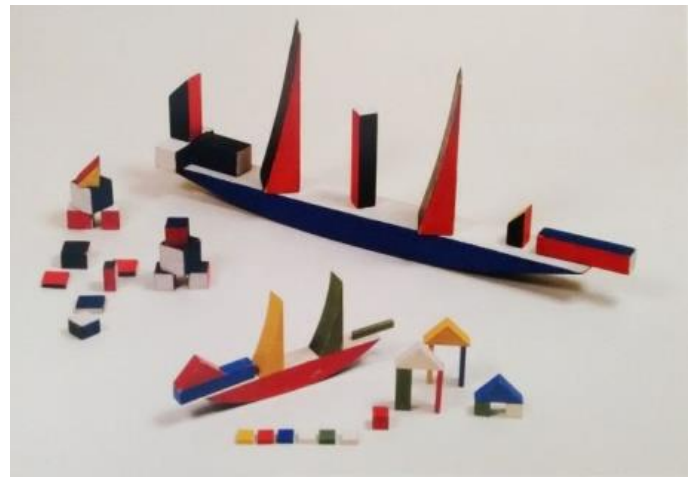

Fonte: MÜLLER, Ulrike. Bauhaus Women. Paris: Flammarion, 2009, (p. 117).

Figura 4 - Carrinho de mão, design Gerrit Rietveld, 1923.

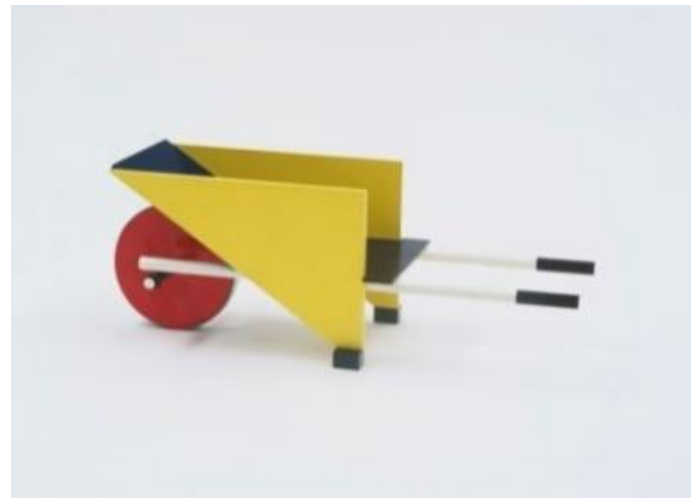

Fonte: designlimaromao.blogspot.com.br (2012)

Com o transcorrer das décadas no século XX outros movimentos como o Pós-modernismo vieram a influenciar a indústria de brinquedos. No design, Ettore Sotssas fundador da empresa italiana Memphis, estava quebrando paradigmas de pensamento e produção. Tinha o objetivo de ir no sentido oposto ao Movimento Funcionalista, onde o design deveria se "libertar da rigidez normativa que dominou o campo durante mais de meio século." (CARDOSO, 2004, p. 206).

Dessa forma, segundo Sudjic (2010), Sottsass se interessava menos por técnica do que por forma e padrão, e usou a cadeira como ponto de partida para uma série interminável de especulações sobre a natureza do ritual e do símbolo. Na visão do autor, Sottsass foi um dos primeiros designers a entender que mesmo através dos aspectos funcionais de um objeto, ainda existe a necessidade psicológica dos significados além da função no mundo contemporâneo.

O design, segundo Sujdic (2010, p. 88 e 89), é considerado uma linguagem principalmente visual, onde a cor pode sugerir uma brincadeira ou seriedade e o formato do objeto para envolver os indivíduos ou sugerir sua função. Mas também, segundo o autor, o design transcende o sentido visual e perpassa por todos os outros sentidos, para finalmente despertar em nós características simbólicas e afetivas.

Um brinquedo não precisa só parecer engraçadinho. Precisa oferecer pelo menos a 
possibilidade de um nível de interação lúdica. Botões para apertar que possam dar uma espécie satisfatória de clique ao serem tocados fazem isso. E também interruptores que piscam quando acionados para cima ou para baixo. (SUDJIC, 2010, p. 88)

Os brinquedos, portanto, neste momento de mudanças, passa a ter outras conotações e significados. Além de representar a cultura material da sociedade, como apontam Mefano (2005) e Moraes (2013), os brinquedos também irão representar valores estéticos e simbólicos. Os brinquedos passam a influenciar a identidade infantil, construindo a partir dos mesmos, a sua percepção do "eu" no espaço em que vive.

Designers de brinquedos fizeram com que os estes se tornassem cada vez mais atrativos. Cores, formas e materiais eram cada vez mais importantes na construção dos objetos a fim de ganhar o consumidor através das lentes do novo, do contemporâneo e do diferente.

Portanto, com o advento da industrialização e com tantas mudanças socioculturais é possível notar que como o brinquedo acompanha essas mudanças e, por consequência, é também cultura material que pode traduzir as implicações culturais e sociais de uma época ou nação, como vimos nos brinquedos bauhausianos. Ou seja, o brinquedo faz parte do processo de se contar a história do homem e da humanidade.

\section{O Século XXI e o Design para a Inclusão Social}

O consumo é incentivado e cresce, pois, exponencialmente pelo mundo que nos cerca de tal maneira que nos faça adquirir artefatos e objetos que nos fazem sentir felizes e bem. Vitrines de loja, propagandas dos meios midiáticos intencionam mostrar uma felicidade contagiante que automaticamente se relaciona com aqueles objetos. O mundo capitalista nos impulsiona gradualmente a fazer compras não apenas com o argumento de realização pessoal na obtenção dos artigos de produtos, mas também pela experiência de compra.

Os encontros dos potenciais consumidores com os potenciais objetos de consumo tendem a se tornar as principais unidades na rede peculiar de interações humanas conhecida, de maneira abreviada por "sociedade de consumidores". Ou melhor, o ambiente existencial que se tornou conhecido como "sociedade de consumidores" se distingue por uma reconstrução das relações humanas a partir do padrão, à semelhança, das relações entre os consumidores e os objetos de consumo. (BAUMAN, 2008, p.19).

O produto e o consumidor, ambos se veem presentes no espaço um para a transmissão de símbolos e subjetividades, que previamente foi projetado a fim de atender os anseios e necessidades do consumidor, e o outro para a recepção e incorporação ao seu contexto de vida. Para Bauman (2008), antes das pessoas comprarem mercadorias, elas próprias são mercadorias a partir do momento que a publicidade finge conhecê-las e acabam por introduzi-las em um universo confuso onde "ter" é mais importante do que "ser".

Neste novo contexto, o design torna-se um elemento-chave para a propagação do consumo a partir do momento em que este materializa os anseios, desejos, necessidades e emoções do consumidor. A aproximação afetiva desses objetos de consumo com o consumidor possibilita que os indivíduos se percebam no espaço. A publicidade compreende muito bem este recurso e lança mão de apelos que levem o consumidor a pensar que o ato de comprar não é uma ação fútil e frívola, muito pelo contrário, ele transpõe significados mais profundos. Portanto o século XXI, é o século em que a compra transcende o objeto. É dessa estratégia que as empresas 
contemporâneas lançam mão. As grandes marcas fazem com que o individuo não associe, inicialmente, a compra apenas pelo produto mas sim a ideia que ele transmite.

\subsection{Brinquedos para inclusão}

Se no século XX a produção de bens de consumo é voltada para fazer com que os usuários sejam captados pela esfera emocional e subjetiva do produto, o século XXI será o momento em que as grandes marcas lançam mão de discursos politicamente corretos e começam a repensar valores sociais e promover discursos ligados a inclusão.

Assim, um exemplo disso são as bonecas Barbies da Mattel. A primeira boneca Barbie é criada em 9 de março 1959, pela empresária Ruth Handler, e durante quase sete décadas imprimiram o ideal da mulher, loira, magra e esbelta. No entanto, no mês de janeiro de 2017, foi lançada a nova coleção que inclui bonecas com diversificados tons de pele cabelos e olhos; diversas alturas (baixas e altas); diversos tipos de corpo (magras e gordas).

Figura 5 - Primeira boneca Barbie, 1959.

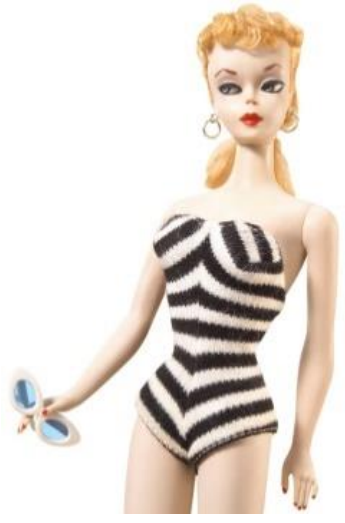

Fonte: br.pinterest.com (2017)

Figura 6 - Nova coleção das bonecas Barbies, 28 de janeiro de 2016.

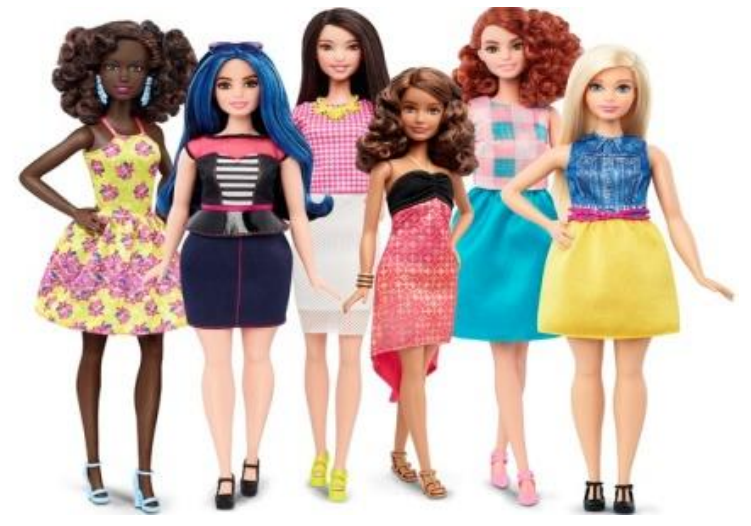

Fonte: g1.globo.com (2016)

Atualmente no mercado podemos perceber a produção de diversos brinquedos que trabalham a temática de inclusão social de crianças com deficiência, como por exemplo bonecas com vitiligo da artesã americana Kay Black. A marca Kay Customz, tem como objetivo despertar a 
questão da inclusão social de meninas que sofrem dessa doença que é caracterizada pela de perda de melanina, ou seja, ocorre a perda pigmentação da pele.

As bonecas são produzidas sob encomenda, inspiradas nas suas futuras donas, que enviam fotos suas à artesã ao fazer o pedido. Até mesmo o contorno das áreas da pele que ficaram esbranquiçadas devido à despigmentação são fielmente reproduzidas nos brinquedos encomendados. (oglobo.globo.com, 2017)

Figura 7- Boneca com vitiligo da artesã Kay Black.

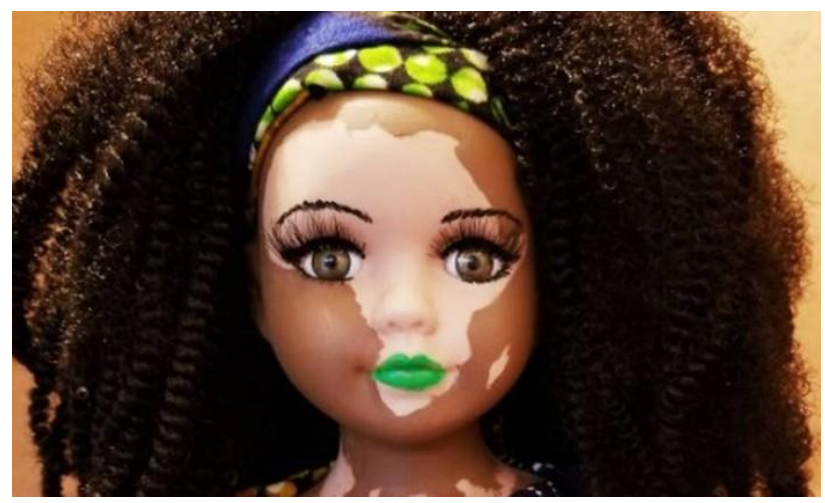

Fonte: oglobo.globo.com

O mundo dos super-heróis que sempre esteve incutido de estereótipos diversos como a beleza, a velocidade e a força encontrada no Super-Homem, por exemplo, ou o poder financeiro e social do civil Bruce Wayne que a noite se veste de Batman para combater o crime na cidade de Gotham. Hoje a indústria de desenhos infantis, do cinema passa abordar novos discursos em que o heroísmo está ligado a outros fatores que não só estéticos e econômicos mas também a quebra de paradigmas como, por exemplo, heróis que tenham uma deficiência física. No imaginário social é comum associar a deficiência a palavras como perda, dependência e fragilidade. Contudo, a empresa britânica Toys Like Me possibilita que o seu cliente crie no site uma maneira na qual as pessoas poderiam fazer o brinquedo segundo as suas necessidades. Você pode fazer bonecos com deficiência física, alterar cor de pele e tipo de cabelo e etc. E o mesmo pode ser feito com os super-heróis, mais conhecidos, podendo ser modificados a gosto do cliente. $O$ personagem $O$ Incrível Hulk de quadrinhos e filmes conhecido como por ser extremamente forte, ganha um saco de colostomia ou um aparelho auditivo, por exemplo.

\footnotetext{
Disponível em: https://oglobo.globo.com/sociedade/artesa-cria-bonecas-com-vitiligo-gera-comocao-nas-redes-
} sociais-21877474. Acesso em: 30 de mar., 2018. 
Figura 8-O Incrível Hulk.

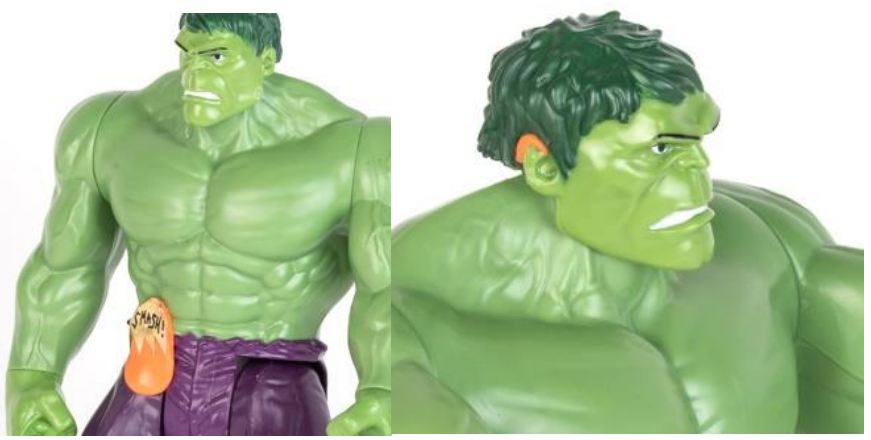

Fonte: toylikeme.org/toys/makeovers

Para as crianças que têm a deficiência é ainda mais significativo, pois as outras crianças do seu meio passam a perceber a deficiência de outra maneira. Mesmo um super-herói forte com superpoderes pode sim ter uma deficiência.

O design tem o poder de incutir em seus objetos ou serviços uma carga simbólica capaz de envolver emocionalmente o consumidor a fim de criar laços com ele. No universo infantil pode-se observar o mesmo. As crianças portam e se cercam de brinquedos e objetos que refletem as suas futuras visões do mundo e que influenciam na construção de suas identidades.

Essas ressignificações nos brinquedos possibilitam não só que novos diálogos sejam criados a cerca da inclusão, mas a autoestima de uma criança que tenha determinada deficiência ou sofra algum tipo de preconceito se sinta mais segura sobre suas características e sua identidade.

\section{Considerações Finais}

Podemos inferir que os indivíduos da sociedade vigente vivem em um contexto da hipermodernidade onde, o processo da alta estetização dos produtos e a experiência que o usuário tem, bem como os significados intangíveis imbuídos neles é a sua maior moeda de valor.

As pessoas compram, portanto, o que lhes trazem algum tipo de prazer, felicidade e autoestima. Essa lógica também se vê inserida no universo infantil. A valorização da infância a partir do século XIX fez com que as crianças se transformassem em um nicho de mercado para a produção em massa no século XX.

O brinquedo perpassa por momentos históricos e épocas que o definem como material cultural da sociedade. Apenas de se olhar um brinquedo podemos inferir de que época ele se trata, como vimos, por exemplo, com os brinquedos da época do Modernismo e Pós-modernismo. Assim, o objeto lúdico carrega diversos símbolos que atravessam o tempo para nos contar histórias. Neste contexto as marcas compreendem que os brinquedos se tornaram fundamentais na expressão de identidades, desejos e anseios de milhares de crianças. E assim, o público infantil se apropria dos brinquedos para contar suas próprias histórias e para dialogarem com o mundo que a cerca através dos mesmos.

Promover o discurso sobre inclusão a partir dos brinquedos se faz relevante não só para que o outro compreenda o sentido de alteridade mas quebrar estigmas acerca do assunto 
diversidade. Portanto, para uma criança que tem deficiência física é imprescindível que o seu lado da história seja contado também, assim como os diversos brinquedos que já abordam diferentes cultuas e etnias em seu escopo. Se ver representada é uma maneira de se aceitar e fazer com que as outras crianças compreendam as diferenças inerentes à natureza humana.

O design se insere como ferramenta poderosa para promover novos diálogos acerca da inclusão social de crianças com deficiência física, no momento em que transforma, por exemplo, um super-herói como o Hulk em um personagem deficiente, ressinifica toda uma cadeia de valores sobre o assunto. Implica em se repensar valores como, o heroísmo, a beleza, a estética, entre outros, na sociedade contemporânea.

A pesquisa em questão tem apoio do órgão de fomento CAPES.

\section{Referências}

ARIÈS, Philippe. História social da criança e da família. 2. ed. Rio de Janeiro: LTC, 2014.

ARRUDA, José Robson de. PILETTI, Nelson. Toda a história: história geral e história do Brasil. São Paulo: Editora Ática, 1999.

BAUMAN, Zigmunt. Vida para consumo: a transformação das pessoas em mercadoria. Rio de Janeiro: Zahar, 2008.

BENJAMIN, Walter. Reflexões sobre a criança, o brinquedo, a educação. São Paulo: Duas Cidades, 2002.

CARDOSO, Rafael. Uma Introdução a Historia do Design. 2oㅡ. São Paulo: Blucher, 2004.

ERNOUT, Alfred e MEILLET, Alfred. Dictionnaire étymologique de la langue latine: histoire des mots. Paris: Librairie C. Klincksiek, 1951.

FERREIRA, Aurélio Buarque de Holanda. Minidicionário da língua portuguesa. Rio de Janeiro: Nova Fronteira, 1993.

MEFANO, Ligea. O Design de Brinquedos no Brasil: Uma arqueologia do projeto e suas origens. 2005. 131f. Dissertação (Mestrado em Design) - Escola de Artes \& Design, Pontifícia Universidade Católica do Rio de Janeiro, Rio de Janeiro.

MORIN, Edgar. Cultura de massas no século XX: Neurose. 9a ed. Vol. 1. Rio de Janeiro: Forense Universitária, 1997.

MÜLLER, U. Bauhaus Women. Paris: Flammarion, S.A. 2009.

ROUSSEAU, Jean-Jacques. Emílio ou da Educação. Rio de Janeiro: Bertrand Brasil, 1995.

SUDJIC, Deyan. A linguagem das coisas. Rio de Janeiro: Intrínseca, 2010.

O Globo. Disponível em: https://oglobo.globo.com/sociedade/artesa-cria-bonecas-com-vitiligogera-comocao-nas-redes-sociais-21877474. Acesso em: 30 de mar., 2018. 